\title{
THE SELECTION AND APPLICATION OF MAGNETIC SEPARATION EQUIPMENT. PART II.
}

\author{
D.G. MORGAN ${ }^{*}$ AND W.J. BRONKALA ${ }^{\dagger}$ \\ Applied Magnetic Systems Inc., Milwaukee, Wisconsin 53220, U.S.A.
}

(Received January 11, 1991)

\begin{abstract}
A survey of magnetic separators and of their selection in application for concentration and purification is given. Wet and dry low-intensity drum separators, magnetic pulleys, induced magnetic roll separator and cross-belt separator are described and selection procedures are outlined.
\end{abstract}

\section{INTRODUCTION}

From the application point of view, magnetic equipment can be divided into three broad categories:

1. Tramp iron removal

2. Magnetic particle separation and concentration

3. Product cleaning.

In Part I [1] of our series the application of magnetic separators to tramp iron removal was discussed. In this article practical aspects of separation and concentration of magnetic particles will be reviewed.

${ }^{*}$ Presently with O.S. Walker Inc., Worcester, Mass., USA 
The type of a magnetic separator used in concentration and purification is influenced by the following factors:
a. Feed condition - wet or dry
b. The mineral to be concentrated or purified
c. Relative magnetic susceptibility of the mineral
d. Feed size
e. The purity to be obtained in either magnetic concentrate or non-magnetic product
f. The capacity to be handled
g. The operating and maintenance costs of the equipment
h. Temperature of the magnet application.

In total number of installed units for mineral concentration, wet magnetic separators far exceed the number of dry magnetic units.

Wet magnetic separators include:

1. Wet drum separators for media recovery in HMS plants

2. Wet drum separators for iron ore concentration

3. High-intensity wet magnetic separators for mineral concentration and clay cleaning.

Dry magnetic separators used in mineral concentration include:

1. Magnetic pulleys

2. Magnetic drums for iron ore concentration and miscellaneous uses

3. Induced-roll high-intensity magnetic separators

4. High-intensity cross-belt magnetic separators

5. Permanent roll magnetic separators.

\section{LOW-INTENSITY WET DRUM MAGNETIC SEPARATORS}

Wet drum magnetic separators are used to recover ferromagnetic solids from a slurry feed. The major areas of usage are in media recovery in HMS plants and in magnetite ore beneficiation. Physical construction of wet drum separators is lightly 
different for the two applications, with the ore concentrator being more rugged in construction and subject to more detailed specifications than the media recovery units. This is particularly true with reference to feed and collection tank design, bearing construction, wear covers on the drums, magnet assembly design and magnetic field strength ratings.

\section{Wet Magnetic Drums for Media Recovery}

In media recovery service the particle size of the feed, particularly the magnetic portion, is quite fine and drum wear is not a serious problem. Maximum magnetic recovery is important and the highest magnetic purity and solids content in the magnetic concentrate is desired.

Factors to consider in selecting a wet drum separator for media recovery service are:

1. Per cent solids in the feed slurry

2. Per cent magnetics in the feed solids

3. Grade of media used in the operating circuit

4. Feed volume $\left(\mathrm{m}^{3} / \mathrm{h}\right)$ to the separator

5. Magnetic discharge rate $(\mathrm{t} / \mathrm{h})$ from the separator

6. Desired magnetic recovery.

Media recovery magnetic drums are conventionally available in $30^{\prime \prime}(762 \mathrm{~mm})$ or $36^{\prime \prime}(914 \mathrm{~mm})$ diameter and in drum widths to $120^{\prime \prime}$ (3050 $\left.\mathrm{mm}\right)$, usually in increments of $300 \mathrm{~mm}$. It is significant to note that the effective width is about 150 $\mathrm{mm}$ smaller than the overall width of a drum. In some instances $48^{\prime \prime}(1219 \mathrm{~mm})$ diameter wet magnetic drums have been used, but the higher capacity of these units does not usually justify the higher costs involved.

Both electro and permanent wet drum separators have been used in media recovery, but permanent magnet assemblies are preferred because of the saving obtained in the elimination of magnet energization power costs.

Both con- and counter-current feed arrangements have been used in media recovery plants. The concurrent drum drum arrangement is usually recommended 
to give the highest magnetic content in the magnetic discharge and usually will provide the highest percentage of solids in this discharge. The counter-current unit will give a slightly higher recovery in some applications, particularly when the magnetic loading is heavy.

\section{Feed Solids Content}

It is desirable for good HMS plant operation to keep your medium as free of fines as possible. This is obtained by effective screening of the HMS vessel feed. Reduced fines will reduce viscosity problems in the medium and result in sharper separation of sink and float products. It also improves magnetic recovery on the magnetic drum separators and gives a cleaner magnetic concentrate.

The use of cyclones in the HMS circuit, either as the HMS vessel or as a densifier for rinse or wash water, increases the solids content and must be evaluated in selecting the media recovery wet drum separators for plants in which cyclones are used.

Typically, a single drum wet separator will be used in plants where the feed solids are in the 10 to 15 per cent range. It is significant to note that extremely dilute feeds make magnetic recovery more difficult and feed volume should by reduced by a factor of 0.5 to 0.75 for such dilute feed.

For solids in the 20 to 25 per cent range either single drum $36^{\prime \prime}$ diameter units or double drum 30 " diameter units are recommended. Above 25 per cent solids, 36" diameter double drum are recommended.

\section{Magnetic Content of Feed Solids}

Typically, the magnetic content of the solids will be 60 per cent or higher. Conventional selection procedure can be used in such cases. When the magnetic content of the solids falls below 60 per cent, the feed volume should be reduced and multi-drum separators considered in order to maintain higher magnetic recovery. 


\section{Media Size}

Media is supplied in several size grades and the grade used will vary with each individual plant. Finer grade improves the stability, but fine particles are more difficult to recover and the feed rate of these finer grade slurries should be reduced by a factor of 0.5 to 0.75 to maintain magnetic recovery. A typical size analysis as used in various HMS plants treating coal is shown in Table I.

TABLE I Typical screen analysis of ground magnetite

\begin{tabular}{rccc}
\hline US Standard Sieve & $\begin{array}{c}\text { Grade 2 } \\
\text { Fine }\end{array}$ & $\begin{array}{c}\text { Grade 3 } \\
\text { Medium }\end{array}$ & $\begin{array}{c}\text { Grade 4 } \\
\text { Coarse }\end{array}$ \\
\hline +50 Mesh & Trace & Trace & $8.8 \%$ \\
$-50+70$ Mesh & $3.8 \%$ & $7.1 \%$ & $8.2 \%$ \\
$-70+100$ Mesh & $4.4 \%$ & $8.8 \%$ & $4.3 \%$ \\
$-100+140$ Mesh & $6.2 \%$ & $11.0 \%$ & $14.1 \%$ \\
$-140+200$ Mesh & $7.6 \%$ & $10.0 \%$ & $12.0 \%$ \\
$-200+325$ Mesh & $13.5 \%$ & $14.7 \%$ & $19.9 \%$ \\
-325 Mesh & $64.5 \%$ & $48.4 \%$ & $32.7 \%$ \\
\hline
\end{tabular}

\section{Recommended Feed Volume}

Both feed volume and magnetic solids discharge rate should be balanced in selecting drum size for media recovery. In Table II typical feed rates are recommended for various single and double wet drum separators.

\section{Magnetic Discharge Rate}

Magnetic discharge rates should not exceed the rates given in Table III, in order to maintain high magnetic media recovery. 
TABLE II Recommended feed volumes

\begin{tabular}{rc}
\hline Separator & Feed rate $\left(\mathrm{m}^{3} / \mathrm{h} / \mathrm{m}\right)$ \\
\hline $30^{\prime \prime}$ diameter single drum & $50-55$ \\
$36^{\prime \prime}$ diameter single drum & $55-70$ \\
$30^{\prime \prime}$ diameter double drum & $55-70$ \\
36 " diameter double drum & $70-95$ \\
\hline
\end{tabular}

TABLE III Recommended discharge rates

\begin{tabular}{ll}
\hline Separator & Maximum discharge rate $(\mathrm{t} / \mathrm{h} / \mathrm{m})$ \\
\hline $30^{\prime \prime}$ diameter drum & 10 \\
$36^{\prime \prime}$ diameter drum & 15 \\
\hline
\end{tabular}

\section{Wet Drum Operating Considerations}

Selection of wet drum separator adhering to the previously discussed selection criteria will produce a media recovery in the 99.6 to 99.9 per cent efficiency range.

There are significant operating considerations that must be maintained to insure these recoveries. Some of the most important considerations are:

1. Maintenance of a reasonably uniform feed rate, and feed distribution across the drum

2. Maintenance of the magnetic discharge point at the proper position. This magnetic discharge point can usually be adjusted slightly, but loose clamp bearings can cause the magnet assembly to fall out of position.

3. Maintenance of a proper operating level in the separator tank. Loss of level or excessive overflow rates can cause serious loss of efficiency of magnetic 
recovery.

4. Drums and tanks should be periodically inspected to determine if holes have developed resulting in leakage into the drum or out of the tank.

Figure 1 illustrates the various drum and tank arrangements used in HMS media recovery plant operations.
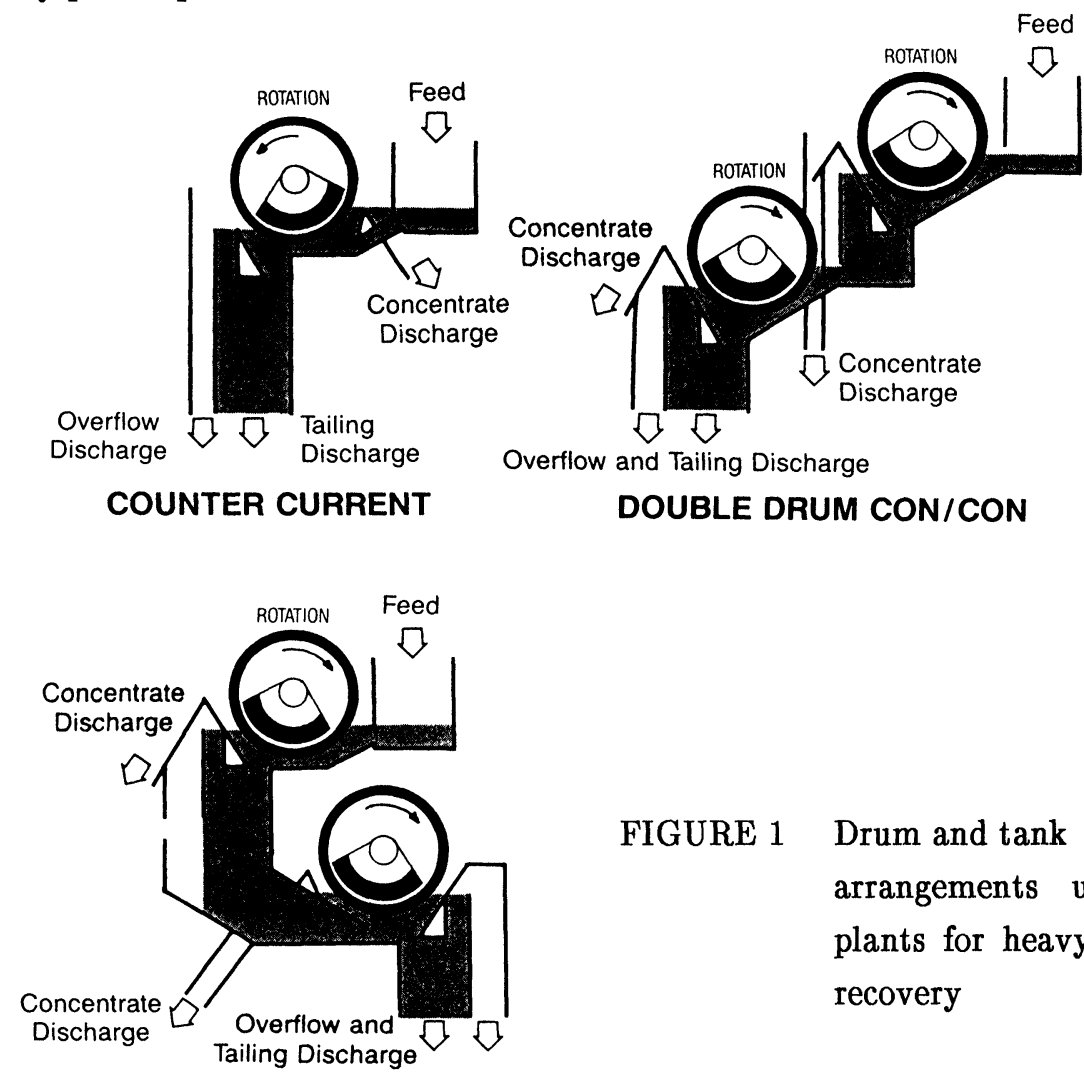

FIGURE 1 Drum and tank arrangements used in plants for heavy media recovery

\section{DOUBLE DRUM CON/COUNTER}

\section{Wet Magnetic Drums For Ore Concentration}

The depletion of direct shipping grade bodies and the demand for higher grade iron ore concentrates led to the usage of magnetic drum separators in the concentration of magnetite ores. These relatively low-magnetic strength drums can also be used to concentrate other minerals having ferromagnetic properties. typically, the ore bodies are relatively low in iron content with the iron minerals finely divided in a gangue matrix. Wet grinding is usually required to liberate the iron minerals although some beach sands may have liberated iron mineral values. 
Wet drum separators are limited to the treatment of material $10 \mathrm{~mm}$ or finer. The magnetic drum separators are usually related to the grinding circuit required to liberate the iron mineral and typically are designed by their application to three basic usages:
a. Cobbers
b. Roughers (cleaners)
c. Finishers.

\section{Cobbers}

Magnetic drums used in cobbing services are designed to obtain maximum rejection of a non-magnetic product and maximum recovery of the iron mineral. Typically, they are applied on a rod mill discharge product. Since the objective is to obtain maximum capacity, these drums are $36^{\prime \prime}$ or 48 " in diameter and they incorporate wear covers on the drum shells to take the wear introduced by the relatively coarse feed size.

Most iron ore concentrating drums are applied in multi-drum configurations so as to obtain maximum rejection of non-magnetic particles. In cobbing service, two drums are typical, but as many as four drums have been used. These drum concentrators incorporate a repulping box ahead of each drum so as to provide the next drum with a feed that can accomplish non-magnetic rejection.

Laboratory or pilot-plant tests are usually conducted on individual ores to determine the number of drums required to obtain optimum concentration results.

\section{Roughers (Sometimes Called Cleaners)}

Magnetic drums used in roughing service are applied after further size reduction has been accomplished on the cobber concentrate. Since the cobber has produced significant upgrading of the ore, the magnetic loading on these drums is significantly increased. Replaceable drum covers are usually used.

Here again, the objective is to obtain rejection of non-magnetics while, at the 
same time, maintaining magnetic recovery. Typically, a double-drum separator will be used in this rougher service and in some plants counter-current or combined con- and counter-current drums are used to maintain magnetic recovery under heavy load. Drums of $36^{\prime \prime}$ or $48^{\prime \prime}$ in diameter are again used in roughing applications.

\section{Finishers}

Magnetic finishing drums are designed to produce the highest possible iron content in the concentrate. Typically, the feed size has been reduced to a nominal -200 or -325 mesh size in a ball mill circuit.

The feed tank and feed arrangement of the finisher separator is usually of the semi-counter-current design with the objective being to disperse the feed particles so as to obtain maximum rejection of non-magnetic particles.

Both $30^{\prime \prime}$ and 36" diameter drums have been used in the finishing applications. Drum covers frequently made of soft rubber are used in the finisher construction.

\section{Factors To Be Considered In Wet Drum Concentrator Selection}

Factors to be considered in the selection of wet drum concentrators are:
a. Feed rate $(\mathrm{t} / \mathrm{h})$
b. Feed size (maximum $10 \mathrm{~mm}$ diameter)
c. Feed volume $\left(\mathrm{m}^{3} / \mathrm{h}\right.$ of pulp)
d. Magnetic content - projected magnetic discharge rate $(\mathrm{t} / \mathrm{h})$
e. Degree of liberation at each stage - size distribution
f. Desired magnetic recovery
g. Magnetic field strength required.

\section{Feed Rate}

Maximum feed rate will vary with the type of separator being considered - cobber, 
rougher or finisher. In concentration applications the capacity must be balanced with the magnetic recovery and non-magnetic rejection. Feed rates for various stages of separation are given in Table IV.

TABLE IV Feed rates for ore concentration

\begin{tabular}{ccc}
\hline Separator & Maximum $(\mathrm{t} / \mathrm{h} / \mathrm{m})$ & Recommended $(\mathrm{t} / \mathrm{h} / \mathrm{m})$ \\
\hline Cobbers & 75 & 45 \\
Roughers & 60 & 45 \\
Finishers & 15 & 15 \\
\hline
\end{tabular}

\section{Feed Size}

Due to feed pan distance usually maintained on wet drum cobbers, the wear encountered with coarser particles and the feed velocities required to move coarse particles, the recommended upper size limits for cobber separators is $10 \mathrm{~mm}$.

Individual ore characteristics required to obtain liberation will determine the feed size in rougher and finisher feeds and in the case of finishers, where all the non-magnetics must be overflowed, a sufficiently fine size to accomplish this overflow must be obtained.

Typical feed sizes for the three applications are shown in Table V.

TABLE V Typical feed size for ore concentration

\begin{tabular}{lc}
\hline Separator & Size Range \\
\hline Cobbers & $-6 \mathrm{~mm}+20$ mesh \\
Roughers & -35 mesh +48 mesh \\
Finishers & -270 mesh +325 mesh \\
\hline
\end{tabular}




\section{Feed Volume}

Feed volume will influence magnetic recovery and will vary with the separation being considered. Feed rates for various stages of separation are given in Table VI.

TABLE VI Feed volume in ore concentration

\begin{tabular}{ccc}
\hline Separator & Maximum $\left(\mathrm{m}^{3} / \mathrm{h}\right.$ & Recommended $\left(\mathrm{m}^{3} / \mathrm{h} / \mathrm{m}\right)$ \\
\hline Cobbers & 100 & 70 \\
Roughers & 100 & 70 \\
Finishers & 35 & 20 \\
\hline
\end{tabular}

\section{Magnetic Content}

The magnetic content of iron ores to be concentrated will vary over fairly wide limits. Ores as low as 10 per cent Fe have been successfully treated and they vary up to ores with 50 per cent or more iron.

Since liberation is not complete at the cobber stage, a substantial amount of attached gangue is carried into the cobber concentrate. Typically, the cobber concentrate will contain 50 per cent or more of iron and, accordingly, the magnetic content of the rougher feed is quite high. Finisher feed contains 2 to 5 per cent of non-magnetics and has a very high magnetic content.

\section{Degree of Liberation}

Complete liberation of most iron ores being treated is usually finer than 100 mesh and some ores have to reduced to -325 mesh for successful concentration. In many instances, reduction to a size suitable for pelletizing is required. 


\section{Desired Magnetic Recovery}

In ore concentration, maximum recovery at all times is desired. Rejection of middling particles might be required, but is difficult to accomplish on wet magnetic drum separators.

\section{Magnetic Field Strength}

There is a considerable debate as to the magnetic field pattern required for the various stages of ore concentration. Several styles of magnet assemblies and a variety of pole combinations are available. Average $50 \mathrm{~mm}$ (2") Gauss readings (average based on readings taken at $50 \mathrm{~mm}$ and made at the centre of each gap and the centre of each pole) of 800 to 1200 Gauss are available on $36^{\prime \prime}$ and $48^{\prime \prime}$ diameter drum separators. Magnetic drums of this strength have operated successfully in commercial plants. Finisher drums are frequently $30^{\prime \prime}$ in diameter and develop average $50 \mathrm{~mm}$ reading of 500 Gauss.

\section{Specifications of Wet Drum Ore Concentrators}

There is a high degree of individual preference among the various users for construction features in the wet magnetic drums purchased for ore concentration plants. The specifications usually include:

1. Number of drums

2. Tank type and arrangement, material of construction

3. Type of magnet assembly, number of poles, electro or permanent

4. Thickness of drum shell, material of construction

5. Construction of drum head, material of construction

6. Bearing type and lubrication arrangement

7. Type and thickness of wear covers

8. Effective magnet width

9. Drum diameter. 


\section{Number of Drums}

The number of drums used in the various applications will vary with the individual ores and the results of pilot-plant or laboratory testwork. Table VII shows typical examples.

TABLE VII Number of drums

\begin{tabular}{ll}
\hline Separator & Number of drums \\
\hline Cobbers & 2 to 4 \\
Roughers & 1 or 2 \\
Finishers & 2 or 3 \\
\hline
\end{tabular}

\section{Tank Type and Material of Construction}

Three basic tank types have been used in ore concentration:

1. Con-current: feed slurry moves in the same direction as the drum rotation

2. Counter-current: feed slurry moves in opposite direction to drum rotation

3. Semi-counter-current: uprising feed with drum moving in a selected direction and all tailings rejected through tank overflow on opposite side of magnetic discharge.

An all-stainless steel series 302 or 304 tank is frequently specified, although composite tanks of stainless and carbon steels have been used successfully.

\section{Types of Magnet Assembly}

Several types of magnet assemblies and pole combinations have been used successfully. Both electro and permanent magnet assemblies have also been used with the permanent assembly frequently preferred because of the power saving effected. Typical pole specifications for the various applications are shown in Table 
VIII.

TABLE VIII Number of poles

\begin{tabular}{cc}
\hline Separator & Number of poles \\
\hline Cobbers & 5 or 6 \\
Roughers & 5 or 6 \\
Finishers & 4 to 10 (normally 5$)$ \\
\hline
\end{tabular}

\section{Thickness and Material of Drum}

The inner drum shell is usually 10 gauge or $3 \mathrm{~mm}$ and is a specified type 302 or 304 stainless steel. Drum heads are usually of high tensile strength aluminium alloy or brass. Recessed head bolts construction with an effective seal is specified. Ball, roller and sleeve type bearings have all been used successfully. Lubrication through the shaft without stopping drum rotation is preferred.

\section{Thickness and Type of Wear Shell}

A butt or lapped type wear shell constructed of non-magnetic stainless steel is preferred for cobber and rougher units. Shells of 10 gauge to $6 \mathrm{~mm}$ thickness have been specified although the shell thickness does influence the surface strength of the magnetic field and should be taken into consideration when the pattern of the magnetic field is specified. Finishers have been operated with both stainless and soft rubber covers and without any cover at all.

\section{Dimensions of the Drum}

The effective width of the magnet is always less than the total width of the drum and must be considered in determining the expected capacity of the unit. 
Drum diameters are typically $30 ", 36^{\prime \prime}$ or $48^{\prime \prime}$. All diameters have been used in various basic applications. In some instances standardization of diameter is specified because of maintenance considerations.

\section{Tank Configurations for Drum Concentrators}

Figure 2 shows a typical double drum cobber arrangement. Figure 3 shows an arrangement of a double-drum finisher.

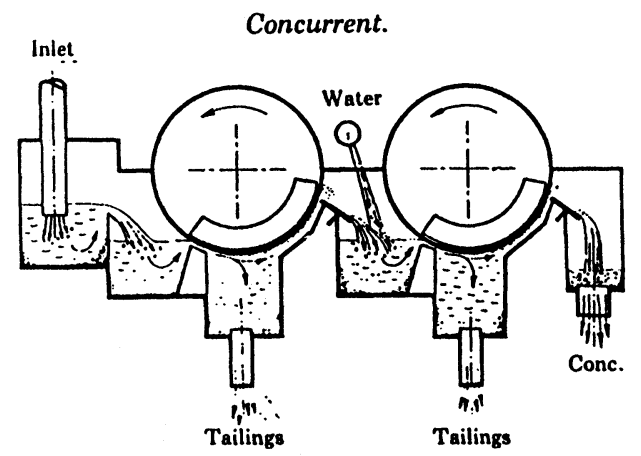

FIGURE 2 A double-drum cobber arrangement

Countercurrent (Steffenson).

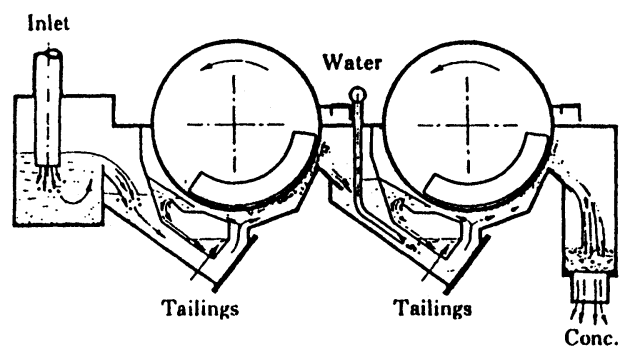

FIGURE 3 A double-drum finisher arrangement

\section{DRY MAGNETIC SEPARATORS}

Commercial types of dry magnetic separators fall into two broad categories. Low-intensity magnetic pulley separators and several types of magnetic drums 
have been used to concentrate iron ore, sponge iron and to recover iron values from steel mill slag. These separators generate effective working magnetic field strength of under 1000 Gauss and are largely limited to the recovery of ferromagnetic materials.

High-intensity dry magnetic separators include three basic types. These ate the induced roll, permanent roll and cross-belt type magnetic separators. High-intensity inductively magnetized disk separator has been used in some areas of the world.

\section{Magnetic Pulleys}

Magnetic pulleys of special design are used in the concentration of magnetite and other ferromagnetic minerals. For the best results, the feed should be screened into various sized fractions and each fraction treated on a separate pulley. Typical feed size would be $+50-100 \mathrm{~mm},+25-50 \mathrm{~mm}$ and $+6-25 \mathrm{~mm}$. The magnetic pulley is not well suited to the treatment of $-6 \mathrm{~mm}$ material, unless of an axial pole design.

Magnetic pulleys are available in both permanent and electro types with the electro sometimes preferred so as to maintain the ability to control the field strength by using a resistor in the dc circuit.

The selection of a magnetic pulley is largely dictated by tonnage to be handled. The feed should be as uniform as possible across the pulley width. Feed size will dictate the diameters of magnetic pulleys used. The larger diameter pulleys develop larger magnetic holding capability as well as a larger radius which improves the holding action of the magnetics on the pulley face. Pulley diameters recommended for various feed sizes are given in Table IX.

\section{$\underline{\text { Magnetic Drums }}$}

Two types of magnetic drums are used in concentration service. These drums vary in the construction of the magnet assembly inside the drum. The first incorporates a magnet assembly in which the poles vary in polarity across the drum width. This 
type of drum develops a strong holding force and is used in treatment of ore up to $200 \mathrm{~mm}$.

TABLE IX Recommended diameters of magnetic pulleys

\begin{tabular}{ccc}
\hline Feed size (mm) & Pulley dia. (inch) & Capacity (t/h/m) \\
\hline $50-100$ & 30 to 36 & $250-400$ \\
$25-50$ & 18 to 24 & $165-250$ \\
$6-25$ & 12 to 18 & $75-135$ \\
\hline
\end{tabular}

The second drum is used for the concentration of finer material, usually $025 \mathrm{~mm}$, and incorporates a magnet assembly of 6 to 55 poles that vary in polarity around the circumference of the drum.

Typically, the magnet assembly of the coarse ore concentrator will have a 180 to $240^{\circ}$ magnet arc. The alternating polarity of the fine ore concentrator causes agitation and reorientation of the magnetic particles as they traverse the magnet arc and produces the maximum cleaning effect.

Selection of drums for treatment of coarse ore is based on capacity to be handled and the size of the particles to be treated. As with magnetic pulleys, a sized feed is desirable for optimum operation. Table $\mathrm{X}$ summarizes the recommended capacity and diameters of drums for coarse ore.

TABLE X Capacities and recommended diameters of dry drums

\begin{tabular}{ccc}
\hline Feed size $(\mathrm{mm})$ & Drum dia. (inch) & Capacity $(\mathrm{t} / \mathrm{h} / \mathrm{m})$ \\
\hline & & \\
$+150-200$ & 60 to 72 & $900-1200$ \\
$+100-150$ & 42 to 48 & $750-900$ \\
$+50-100$ & 30 to 36 & $250-400$ \\
$+6-50$ & 12 to 18 & $75-135$ \\
\hline
\end{tabular}




\section{Magnetic Drum for Fine Ore Treatment}

The alternating polarity drums are used for the concentration of $-25 \mathrm{~mm}$ ores. These drums are available in both electro and permanent magnet types, with permanent units usually used on ore finer than $12 \mathrm{~mm}$. The field strength of the electro drum assembly can be regulated by putting a control resistor in the magnetic circuit. control of the performance of the permanent magnet drum can be regulated to some degree by use of a variable speed drum drive motor.

A variety of magnet pole configuration are available. The electro alternating polarity drums are available in 18 to $36^{\prime \prime}$ diameter with 7 to 55 poles. Multi-drum treatment is frequently used in alternating polarity drum separation both to obtain additional magnetic recovery and improved magnetic cleaning.

The physical arrangement of multipole drums will depend on the end objective of the separation with the primary magnetic concentrate re-treated on the secondary drum where the maximum cleaning is required and the secondary drum re-treating the primary non-magnetic product where maximum recovery is required.

Magnetic drum selection of alternating polarity drum separators is based on capacity to be handled and the particle size of the feed. Recommended capacities and the selection of the type of the drum are given in Table IX. A typical high-speed double-drum arrangement is shown in Figure 5.

TABLE XI Selection of a dry drum separator

\begin{tabular}{cccc}
\hline $\begin{array}{c}\text { Feed size } \\
(\mathrm{mm})\end{array}$ & Drum type & No. of poles & $\begin{array}{c}\text { Capacity } \\
(\mathrm{t} / \mathrm{h} / \mathrm{m})\end{array}$ \\
\hline$+12-25$ & $\begin{array}{c}24-30^{\prime \prime} \\
\text { electro or permanent } \\
30^{\prime \prime} \text { permanent }\end{array}$ & 6 to 8 & $75-90$ \\
$+6-12$ & $\begin{array}{c}8 \text { to } 30 \\
10 \text { to } 55\end{array}$ & $\begin{array}{c}45-75 \\
15-60\end{array}$ \\
\hline
\end{tabular}




\section{High-Intensity Induced Roll Magnetic Separator}

Induced roll magnetic separators of many configurations have been designed and constructed. Both overfed and underfed roll designs have been built, with the latter used to obtain a higher degree of cleaning at relatively high capacity. The typical induced roll usage is for cleaning of such materials as silica sand and feldspar. Due to narrow magnetic operating gap, the feed size to induced roll separators is limited to material finer than $3 \mathrm{~mm}$.

Further, because of the surface activity of very fine material, there should be little 200 mesh material present unless the loss of this material in the magnetic concentrate can be tolerated.

Induced roll separators have also been used in the concentration and cleaning of heavy minerals found in beach sands such as rutile, ilmenite and chromite, in combination with high-tension electrostatic separators.

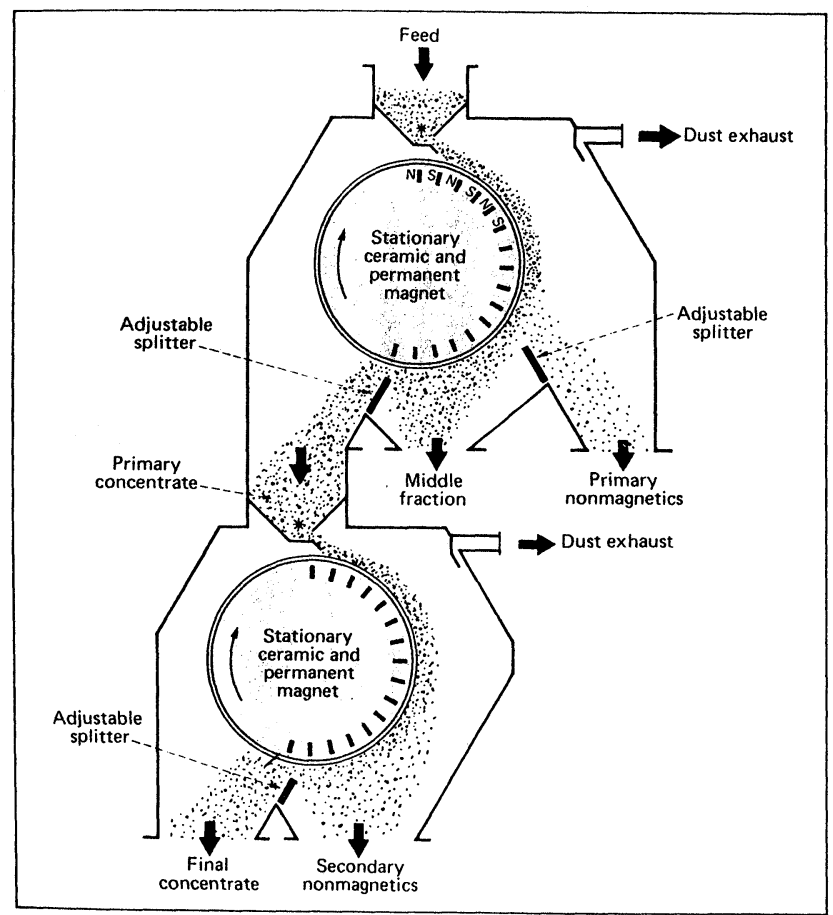

FIGURE 4 Alternating-polarity double-drum magnetic separator for fine particle treatment 
For selective removal of minerals which vary in magnetic susceptibility, or to obtain maximum removal of contaminants in silica sand or feldspar, multi-stage induced roll separators are applied. Induced rolls from a single roll to as many as seven rolls arranged in series are available. The roll width is limited to $750 \mathrm{~mm}$, largely due to deflection forces exerted in the induced roll by the strong magnetizing forces. Field strength up to 20 kGauss is developed in the working gap.

Selection of the induced roll magnetic separator will be influenced by the end objective of the separation and the capacity to be handled. There is no standard roll diameter, although $100 \mathrm{~mm}$ rolls are most frequently used in magnetic cleaning service such as silica sand cleaning. The principle of operation of the induced roll magnetic separator in shown in Figure 5.

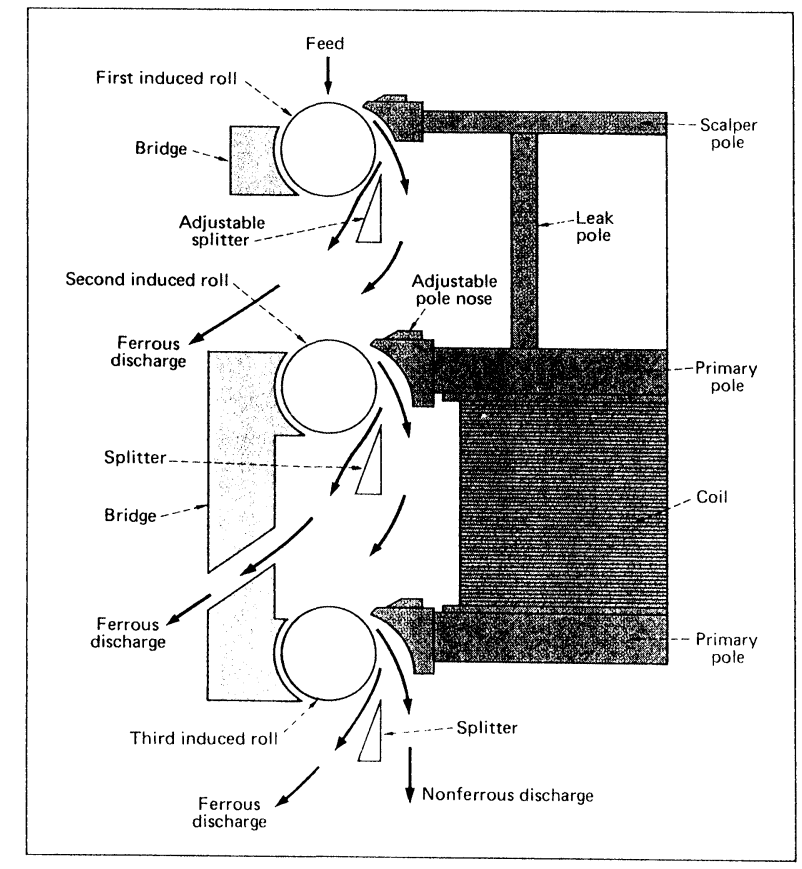

FIGURE 5 Induced-roll magnetic separator

Recommended capacities for $100 \mathrm{~mm}$ roll diameter are 2 to $4 \mathrm{t} / \mathrm{h} / \mathrm{m}$ of the roll width, for cleaning operations, and 1 to $2 \mathrm{t} / \mathrm{h} / \mathrm{m}$ for concentrating service. The number of magnetic heads to be used will vary with the application and is largely determined by preliminary testing. For silica sand cleaning a 3 to 5 pole machine 
is recommended in most cases. The primary pole of most induced-roll separators usually utilizes leak links of flux from the high-strength energizing coil so as to develop a moderate strength primary pole. This pole will remove ferromagnetic particles which tend to accumulate and block the secondary poles when they are not removed.

\section{High-Intensity Cross-Belt Magnetic Separator}

For very selective concentration of weakly magnetic minerals, the high-intensity cross-belt separator has been utilized. This separator employs

a feed belt on which a thin layer of the feed material is introduced to a high-intensity magnetic field, in which a magnetic material is lifted to the upper pole of the field and transferred by a cross-belt to a collective hopper.

To obtain a high-field gradient, required for separation of weakly magnetic minerals, the upper pole is shaped to a point or series of points, for improved capacity, with the bottom pole being flat.

In case where a variety of weakly magnetic minerals are to be concentrated, a series of high-intensity poles will be utilized with increasing field strength at each succeeding pole or using a variation in the air gap. The principle of operation of the high-intensity cross-belt separator is shown in Figure 6.

The cross-belt separator has been used to concentrate such high value minerals as ilmenite, wolframite, monazite, xenotite, columbite, tantalite and many others.

The use of a lift action provides a high degree of selectivity with a minimum entrapment of non-magnetic minerals. Because the accumulation of the magnetics at the high-intensity point creates a build-up across the belt width, the cross-belt magnet width is limited to $600 \mathrm{~mm}$. The feed is, at most, a few particles deep and accordingly the feed rates are limited to about $2 \mathrm{t} / \mathrm{h} / \mathrm{m}$ of the width of the feed belt, with lower capacities required for the cleaning of very weakly magnetic minerals.

A variable speed drive is usually used on the feed and cross-belt drives to exercise control in the operation of the separator, although the speed is not usually changed 
once the optimum operating conditions are established.

Feed rates and selection of the number of magnetic heads are usually determined by preliminary laboratory tests. The types of minerals involved in the feed largely determine the number of poles that will be selected. high-intensity cross-belt separators are frequently used in combination with induced-roll or electrostatic separators.

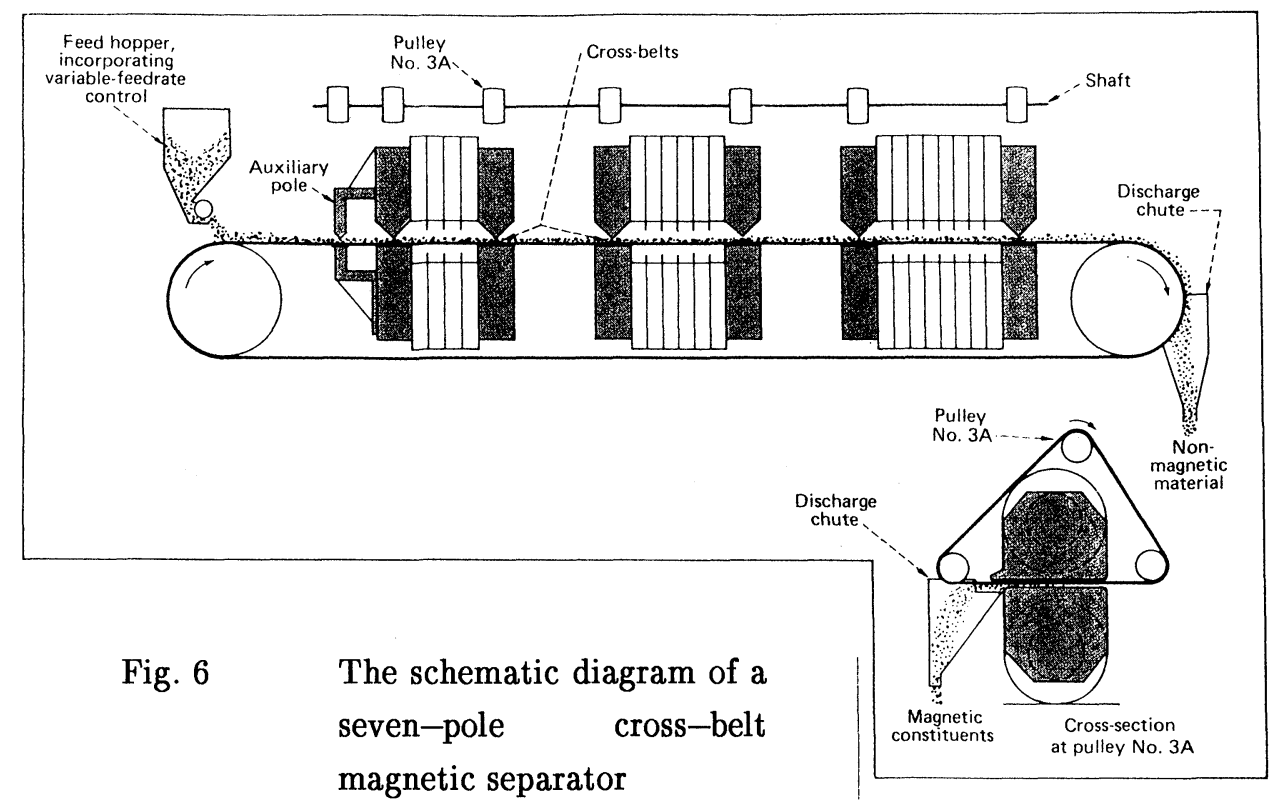

\section{REFERENCE}

[1] D.G. Morgan and W.J. Bronkala: Mag. Electr. Sep. 3 (1991), 5

D.G. Morgan and W.J. Bronkala: For biographies see Mag. Electr. Sep. 3 (1991), 16 and 54 , respectively.

Keywords: magnetic separator, drum separator, heavy media, magnetic pulley, induced-roll separator, cross-belt separator 